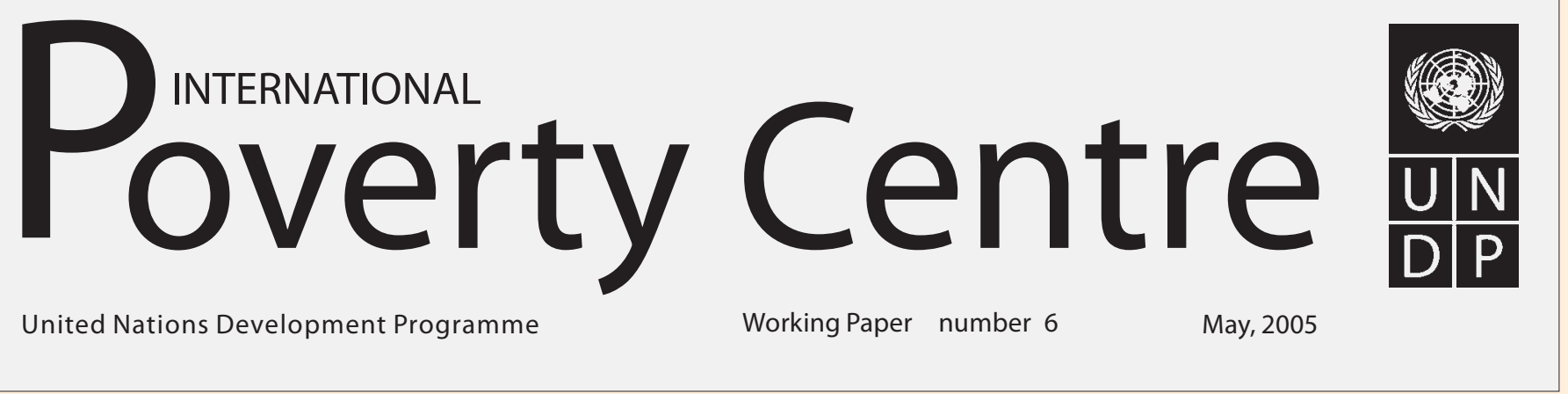

\title{
ON ASSESSING PRO-POORNESS OF GOVERNMENT PROGRAMMES: INTERNATIONAL COMPARISONS
}

\author{
Nanak Kakwani \\ Director/Chief Economist, \\ International Poverty Centre, \\ United Nations Development Programme \\ and \\ Hyun H. Son \\ Visiting Fellow \\ International Poverty Centre, \\ United Nations Development Programme
}




\title{
Copyright $\odot 2005$
}

United Nations Development Programme International Poverty Centre

\author{
International Poverty Centre \\ SBS - Ed. BNDES, $10^{\circ}$ andar \\ 70076900 Brasilia DF \\ Brazil
}

povertycentre@undp-povertycentre.org

www.undp.org/povertycentre

Telephone +55 6121055000

Fax +556121055001

\section{Rights and Permissions}

All rights reserved.

The text and data in this publication may be reproduced as long as the source is cited.

Reproductions for commercial purposes are forbidden.

The International Poverty Centre's Working Papers disseminates the findings of work in progress to encourage the exchange of ideas about development issues. Our main objective is to disseminate findings quickly, so we compromise and bear with presentations that are not fully polished. The papers are signed by the authors and should be cited and referred accordingly. The findings, interpretations, and conclusions expressed in this paper are entirely those of the authors. They do not necessarily represent the view of the International Poverty Centre or the United Nations Development Programme, its Administrator, Directors, or the countries they represent.

Working Papers are available online at http://www.undp.org/povertycentre and subscriptions might be requested by email to povertycentre@undp-povertycentre.org 


\title{
ON ASSESSING PRO-POORNESS OF GOVERNMENT PROGRAMMES: INTERNATIONAL COMPARISONS*
}

\author{
Nanak Kakwani and Hyun H. Son ${ }^{* *}$
}

\begin{abstract}
This paper proposes a new "Pro-Poor Policy (PPP)" index, which measures the pro-poorness of government programmes, as well as basic service delivery in education, health and infrastructure. The index provides a means to assess the targeting efficiency of government programmes compared to perfect targeting. The paper also deals with the policy issue of how targeting efficiency of government programmes varies across various socioeconomic groups. To this effect, the paper develops two types of PPP indices by socioeconomic groups, which are within-group and total-group PPP indices. The within-group PPP index captures how well targeted a programme is within a group. On the other hand, if our objective is to maximize poverty reduction at the national level, the targeting efficiency of particular group should be judged on the basis of total-group PPP index. Using micro unit-record data on household surveys from Thailand, Russia, Vietnam, and 15 African countries, the paper evaluates a wide range of government programmes and basic services.
\end{abstract}

Keywords: Targeting, Universal, Pro-Poor, Poverty

JEL Classification: C15, I32

\footnotetext{
* We would like to acknowledge helpful comments received from Professors David Gordon and K. Sundaram.

** Email address for correspondence: hyun.son@undp-povertycentre.org.
} 


\section{INTRODUCTION}

Many governments in developing countries are increasingly considering introducing safety net programmes that provide income to the poor or those who face a probable risk of falling into poverty, in the absence of the cash or in-kind transfers provided by such programmes. In designing such programmes, governments in developing countries are often faced with the choice between cash and in-kind transfers. Economic theory would lead us to believe that cash transfers are the preferred means of assistance. A range of economic as well as administrative considerations influence this choice (Grosh 1994, Jimenez 1993, Tabor 2002).

Whether the transfer programmes are cash or in-kind, it is obvious that if our objective is to reduce poverty, the transfer programmes should be designed in a way that they lead to the maximum reduction in poverty under given resource constraints. To achieve this objective, perfect targeting will be an ideal solution when (i) only the poor get all the benefits, and (ii) benefits given to the poor are proportional to their income shortfall in relation to the poverty line. To implement such a programme, however, we will need to have detailed information on people's incomes or consumption. "Such detailed information, and the administrative ability to use it is not present in most developing countries" (Haddad and Kanbur 1991). We generally resort to a proxy targeting, which makes the transfers based on easily observable socioeconomic characteristics of households. The proxy targeting can never achieve 100 percent targeting efficiency. It is, therefore, important to know how good the proxy targeting is compared to perfect targeting. In this paper, we provide a methodology to assess the targeting efficiency of government programmes, which can be cash or in-kind.

A government programme may be defined as pro-poor if it provides greater absolute benefits to the poor compared to the non-poor. Obviously, with a given fixed cost, a pro-poor programme will lead to greater poverty reduction than a non-pro-poor programme. Suppose there are two programmes $A$ and $B$ incurring the same cost, then $A$ will be more pro-poor than $B$ if it leads to a greater poverty reduction than $B$. Utilizing this definition, the paper develops a new index called "Pro-Poor Policy (PPP)" index, which measures the pro-poorness of government programmes, as well as basic service delivery in education, health, and infrastructure.

The PPP index is defined as the ratio of actual proportional poverty reduction from a government programme, to the proportional poverty reduction that would have been achieved in a counterfactual situation when every individual in society had received exactly the same benefits from the programme. The value of the PPP index, framed in the realm of perfect targeting, provides a means to assess the targeting efficiency of government programmes.

From the policy point of view, it is important to know how targeting efficiency of government programmes varies across various socioeconomic groups. To answer this question, the paper develops two types of PPP indices by socioeconomic groups, which are within-group and total-group PPP indices. While the within-group PPP index measures the propoorness of a programme within the group, the total-group PPP index captures the impact of operating a programme in the group on its pro-poorness at national level. The within-group PPP index captures how well targeted a programme is within a group. On the other hand, if our 
objective is to maximize poverty reduction at the national level, the targeting efficiency of particular group should be judged on the basis of total-group PPP index.

Using micro unit-record data on household surveys from Thailand, Russia, Vietnam, and 15 African countries, the paper evaluates a wide range of government programmes and services.

The paper is organized in the following manner: Section 2 describes poverty measures. Section 3 is devoted to the derivation of the Pro-Poor Policy (PPP) index to measure the propoorness of governments' welfare programmes and utilization of basic services. Section 4 formulates the values of the PPP index attainable under perfect targeting and Section 5 proposes the PPP index by socioeconomic groups. While Section 6 presents empirical results applied to Thailand, Russia, and Vietnam, Section 7 provides an empirical analysis for 15 African countries. The final section summarizes the major findings emerging from the study.

\section{POVERTY MEASURES}

We calculate the pro-poorness of a government policy by measuring its impact on poverty. If there are two policies $A$ and $B$, then policy $A$ is more (less) pro-poor than policy $B$ if it achieves a greater (smaller) reduction in aggregate poverty for a given cost. Aggregate poverty can be measured in a variety of ways. In this paper, we will focus on a class of additively separable poverty measures that can be written as

$$
\theta=\int_{0}^{z} P(z, x) f(x) d x
$$

where $x$ is the income of an individual, which is a random variable with a density function $f(x)$. An individual is identified as poor if his/her income is less than the poverty line $z . P(z, x)$ may be interpreted as the deprivation suffered by an individual with income $x$ and is a homogenous function of degree zero in $z$ and $x$, which satisfies the restrictions:

$$
\begin{gathered}
P(z, x)=0 \quad \text { if } x \geq z \\
\frac{\partial P(z, x)}{\partial x}<0 \text { and } \frac{\partial^{2} P(z, x)}{\partial x^{2}}>0
\end{gathered}
$$

Individuals do not suffer any deprivation when their income or consumption can meet their basic minimum standard of living defined by the poverty line. $\theta$ in (1) measures the average deprivation suffered by the society due to the existence of poverty.

Foster, Greer, and Thorbecke (1984), for example, proposed a class of poverty measures that is obtained by substituting 


$$
P(\mathrm{z}, \mathrm{x})=\left(\frac{z-x}{z}\right)^{\alpha}
$$

in (1), where $\alpha$ is the parameter of inequality aversion. When $\alpha=0,1$ and 2, the poverty measure is a headcount ratio, poverty gap ratio and severity of poverty index, respectively.

To formulate a poverty reduction policy, we need to make a choice of poverty measures. For instance, the headcount ratio will require different policies than poverty gap and severity of poverty. The headcount ratio is a crude measure of poverty because it completely ignores the gap in incomes from the poverty line and the distribution of income among the poor. The severity of the poverty index has all the desirable properties.

\section{PRO-POOR POLICY INDEX}

Suppose there is a welfare transfer from the government, which leads to an increase in the recipients' income or consumption expenditure. Accordingly, there will be a reduction in poverty incurred from the increase in income. Suppose $x$ is the income of a person before transfer and $b(x)$ is the benefit received by the person with income $x$, the percentage change in poverty (because of this benefit) can be written as:

$$
\frac{d \theta}{\theta}=\frac{1}{\theta} \int_{0}^{z} \frac{\partial P}{\partial x} b(x) f(x) d x
$$

We define a government programme to be pro-poor if the poor receive greater absolute benefits than the non-poor. It means that the pro-poor government programme should achieve greater poverty reduction compared to a counter-factual situation where everyone receives exactly the same benefit from the programme.

Suppose that the average or mean benefit generated from the government programme is denoted by $\bar{b}$. The percentage change in aggregate poverty, when the amount of $\bar{b}$ is given to everyone, can be written as:

$$
\frac{d \theta}{\theta}=\frac{\bar{b}}{\theta} \int_{0}^{z} \frac{\partial P}{\partial x} f(x) d x
$$

We define the pro-poor policy index as the ratio of actual proportional poverty reduction from the programme as given in (3), to the proportional poverty reduction that would have been achieved if every individual in society had received exactly the same benefits (equal to the average benefit from the programme) as given in (4). Thus, the pro-poor policy index can be expressed as 


$$
\lambda=\frac{1}{\bar{b} \eta \theta} \int_{0}^{z} \frac{\partial P}{\partial x} b(x) f(x) d x
$$

where

$$
\eta=\frac{1}{\theta} \int_{0}^{z} \frac{\partial P}{\partial x} f(x) d x
$$

is the absolute elasticity of poverty: if everyone receives one unit of currency, then poverty will change by $100 \times \eta$ percent.

A programme will be called pro-poor (anti-poor) when $\lambda>1(<1)$. The larger the value of $\lambda$, the greater will be the degree of pro-poorness of the programme.

To calculate $\lambda$, programme does not have to be a programme of cash transfers. As a matter of fact, a large number of government programmes consist of providing various services in the areas of education, health and other social services. Although these services do not provide cash to individuals, they do contribute to their standard of living. Hence, it can be assumed that if a person utilizes a government service, then he/she receives some notional cash. If all individuals who utilize a government service are assumed to receive exactly the same benefits (in the form of notional cash), then we can easily calculate the pro-poor policy index $\lambda$, by defining $b(x)=1$, if a person is utilizing a service and 0 otherwise.

\section{PERFECT TARGETING}

The PPP index has the lowest value of zero if the government programme does not reduce any poverty at all, which will happen when all benefits of the programme go to the non-poor. This situation can be described as:

$$
\begin{array}{ll}
b(x)=0 & \text { if } x<z \\
b(x) \geq 0 & \text { if } x \geq z
\end{array}
$$

Substituting (7) into (5) gives $\lambda=0$. This is the extreme situation of imperfect targeting.

Perfect targeting may be defined as a situation when (i) only the poor receive all the benefits, and, (ii) benefits given to the poor are proportional to the income shortfall from the poverty line. This situation may be described as:

$$
\begin{array}{ll}
b(x)=k(z-x) & \text { if } x<z \\
b(x)=0 & \text { if } x \geq z
\end{array}
$$


When $k=1$, poverty is completely eliminated. $k$ should be less than 1 in order to preserve incentives for people to work. Per capita cost of such a programme, which excludes administrative costs, is given by

$$
\begin{aligned}
& \bar{b}=k \int_{0}^{z}(z-x) f(x) d x \\
& \lambda, \text { in this situation, is derived from (5) as } \\
& \lambda_{m}=\frac{1}{\bar{b} \eta \theta} \int_{0}^{z} \frac{\partial P}{\partial x}(z-x) f(x) d x
\end{aligned}
$$

where $\lambda_{m}$ is the value of PPP index obtainable in the case of perfect targeting. Note that in the computation of $\lambda_{m}$, we do not need to assume one single poverty line for all households. Every household can have different poverty lines depending on the household composition and the regional prices faced by the households. In our empirical study of Thailand, the official poverty line varies with households, but in the case of Vietnam, the poverty line is fixed for all households. If we assume that all households have the same per capita poverty line, then by substitutions it is easy to demonstrate that the value of $\lambda_{m}$ for the poverty gap ratio is equal to the inverse ratio of the headcount index $H$ (i.e. $1 / H$ ). Similarly, it can be easily proved that $\lambda_{m}$ for the severity of poverty index is equal to $\frac{s}{g^{2}}$, where $g$ is the poverty gap ratio and $s$ is the severity of poverty index. ${ }^{1}$

Thus, we have obtained the values of $\lambda$ attainable under the situation of perfect targeting. In practice, it is not possible to attain perfect targeting because it is difficult to obtain accurate data concerning people's income or consumption. We generally resort to proxy targeting such as by geographical regions or by other socioeconomic characteristics of households. Since the value of $\lambda_{m}$ can be easily calculated from (9), we can then judge the target efficiency of a programme by comparing it with its value attainable under perfect targeting.

\section{PPP INDEX BY SOCIOECONOMIC GROUPS}

Suppose that there are $K$ mutually exclusive socio-economic groups in the population, then the PPP index for the $k$ th group can be obtained from equation (5) as:

$$
\lambda_{k}=\frac{1}{\overline{b_{k}} \eta_{k} \theta_{k}} \int_{0}^{z} \frac{\partial P}{\partial x} b(x) f_{k}(x) d x
$$

where $\bar{b}_{k}$ is the mean benefit of the programme in the $k$ th group, $\theta_{k}$ is the poverty measure in the $k$ th group and and $f_{k}(x)$ is the density function of the $k$ th group and $\eta_{k}$ is the absolute elasticity of the poverty of the $k$ th group: 


$$
\eta_{k}=\frac{1}{\theta_{k}} \int_{0}^{z} \frac{\partial P}{\partial x} f_{k}(x) d x
$$

which is the proportional change in poverty within the kth group when everyone in the $k$ th group receives one unit of currency.

If $a_{k}$ is the population share of the $k$ th group, such that $\sum_{k=1}^{K} a_{k}=1$, then

$$
f(x)=\sum_{k=1}^{K} a_{k} f_{k}(x)
$$

Utilizing (5), (10), (11) and (12) easily gives

$$
\lambda=\frac{1}{\bar{b} \eta \theta} \sum_{k=1}^{K} \bar{b}_{k} \eta_{k} \theta_{k} a_{k} \lambda_{k}
$$

which shows that the PPP index for the whole country is the weighted sum of the PPP indices for the individual groups.

$\lambda_{k}$ measures the degree of pro-poorness of a programme within the $k$ th group. Although this index, (which we call within-group PPP index), is useful in knowing how well targeted a programme is within a group, it does not tell us whether targeting the $k$ th group will necessarily lead to a pro-poor outcome at national level. Since our objective is to achieve the maximum reduction in poverty at the national level, we need to see the impact of targeting the kth group on national poverty. To capture this effect, we derive below a totalgroup PPP index for the $k$ th group.

Since the poverty measures given in (1) are additively decomposable, we can express the total poverty in country as the weighted average of poverty in individual groups with weights proportional to their population shares:

$$
\theta=\sum_{k=1}^{K} a_{k} \theta_{k}
$$

where $a_{k}$ is the population share of the $k$ th group such that $\sum_{k=1}^{K} a_{k}=1$ and $\theta_{k}$ is the poverty measure in the $k$ th group. Differentiating (14) in both sides gives 


$$
\frac{d \theta}{\theta}=\sum_{k=1}^{K}\left(\frac{a_{k} \theta_{k}}{\theta}\right)\left(\frac{d \theta_{k}}{\theta_{k}}\right)
$$

Suppose a programme $b(x)$ operates only in the $k$ th group, then the proportional change in poverty in the $k$ th group will be given by

$$
\frac{d \theta_{k}}{\theta_{k}}=\frac{1}{\theta_{k}} \int_{0}^{z} \frac{\partial P}{\partial x} b(x) f_{k}(x) d x
$$

where $f_{k}(x)$ is the density function of the $k$ th group. Utilizing (16) into (15), we obtain the proportional change in national poverty, when the government programme operates only in the $k$ th group, as:

$$
\left(\frac{d \theta}{\theta}\right)_{k}=\frac{a_{k}}{\theta} \int_{0}^{z} \frac{\partial P}{\partial x} b(x) f_{k}(x) d x
$$

Suppose $\bar{b}_{k}$ is the mean benefit of the program in the $k$ th group. So, the total cost per person (in the whole population) of operating the programme in the $k$ th group is given by $a_{k} \bar{b}_{k}$. If we had considered a scenario of universal targeting of the whole population providing every individual the benefit equal to $a_{k} \bar{b}_{k}$, then the proportional reduction in national poverty would have been $a_{k} \bar{b}_{k} \eta$. Obviously then, operating programmes in the $k$ th group will be propoor if the magnitude of poverty reduction in (17) is greater than the poverty reduction obtained with universal targeting, while incurring the same cost. Thus, we define the totalgroup PPP index for the $k$ th group as:

$$
\lambda^{*}{ }_{k}=\frac{1}{\bar{b}_{k} \eta \theta} \int_{0}^{z} \frac{\partial P}{\partial x} b(x) f_{k}(x) d x
$$

Operating the government programme $b(x)$ in the $k$ th group is pro-poor (anti-poor) if $\lambda_{k}^{*}$ is greater (less) than 1 . Note that $\lambda_{k}^{*}$ measures the pro-poorness of the programme in the kth group with respect to the whole population and not with respect to the population within the $k$ th group.

Utilizing (5), (12) and (18) easily gives the following:

$$
\lambda=\frac{1}{\bar{b}} \sum_{k=1}^{K} \bar{b}_{k} a_{k} \lambda_{k}^{*}
$$


which shows that the pro-poor policy index for the whole country is the weighted average of the total-group PPP indices for the individual groups, with weight proportional to shares of benefits received by each group.

Equation (19) demonstrates that to reduce poverty at national level, operating the government programme in some groups will be more efficient than in other groups. This efficiency can be captured by the value of $\lambda^{*}{ }_{k}$ : the larger the value of $\lambda^{*}{ }_{k}$, the more efficient is the $k$ th group in reducing the national poverty. On the whole, the methodology presented here can help us to identify the socioeconomic groups that should be targeted in order to achieve maximum reduction in national poverty.

\section{CASE STUDIES I: THAILAND, RUSSIA AND VIETNAM}

In this section we apply our methodology suggested in Sections 3 to 5 to three countries: Thailand, Russia and Vietnam. While the pro-poor policy (PPP) index is applied to Thailand and Russia to capture the extent to which the governments' welfare schemes benefit the poor, the PPP index is applied to Vietnam to estimate the degree of effectiveness of basic services including education and health - utilized by the population.

For all three countries, we utilized nation-wide household surveys covering the periods of 2000, 2002, and 1997-98 for Thailand, Russia and Vietnam, respectively. Poverty lines are country-specific. While a single average national poverty line is used for Vietnam, Thai and Russian poverty lines differ across households because they take into account different needs of household members by gender and age, as well as spatial costs of living across regions and areas in both Thailand and Russia. ${ }^{2}$

\subsection{WELFARE PROGRAMMES IN THAILAND AND RUSSIA}

\section{THAILAND}

In recent years, the Thai government has implemented a few social welfare programmes, including social pensions for the elderly, low-income medical cards, health insurance cards, and free school lunch programmes. These are means tested and designed specifically to target the low-income group. In this section we examine whether these welfare programmes have indeed benefited poor people in the society by means of our proposed PPP index.

Table 1 presents the Pro-Poor Policy (PPP) index for Thailand's social welfare programmes. As can be seen from the table, all four welfare programmes have the value of the PPP index greater than 1. On this account, we may conclude that all the four welfare programmes benefit the poor more than the non-poor. Overall, the poor have greater access to government welfare programmes than the non-poor. 
TABLE 1:

Pro-Poor Policy Index for welfare programs in Thailand: 2000

\begin{tabular}{lcc}
\hline Welfare schemes & Poverty gap ratio & Severity of poverty \\
\hline Social pension for the elderly & 1.68 & 1.54 \\
Low-income medical cards & 2.02 & 2.12 \\
Health insurance cards & 1.29 & 1.25 \\
Free school lunches & 2.02 & 2.06 \\
& & 10.31 \\
Perfect targeting & 6.77 & 1.24 \\
\hline Universal social pensions (for elderly over 65 years of age) & 1.21 & \\
\hline
\end{tabular}

It is interesting to note that the welfare programmes - low-income medical cards and free school lunches - have higher values of the PPP index for the severity of poverty measure. Since the severity of poverty measure gives greater weight to the ultra-poor, the absolute benefits of low-income medical cards and free school lunch programmes flow to the ultrapoor more than the moderately poor.

We have also calculated the PPP index in the hypothetical case of a universal pension system. Suppose that every elderly person over 65 years of age receives a pension from the government. Is this scenario more pro-poor than the actual pension system? The PPP index indicates that although a universal pension scheme for the elderly is pro-poor and is even more beneficial to the ultra-poor, the present pension system is far more pro-poor than the universal one. This implies that the current means-tested pension system provides more benefits to the poor than the universal pension system for people of 65 years of age and over. In this analysis, we have not taken into account administrative costs involved in providing mean-tested pensions.

Perfect targeting is the ideal policy for poverty reduction. In practice, it is not feasible to operate such a policy because: (i) the administrative cost is very high; and (ii) it is difficult to obtain accurately details of individuals' income or consumption particularly in the countries, where the informal sector might be very large. If the government in Thailand had succeeded in implementing perfect targeting, the PPP index would have been 6.77 for the poverty gap and 10.31 for the severity of poverty measure. Thus, the Thai welfare programmes, although propoor, have much lower values on the PPP index than the values that would have been obtained with perfect targeting. This suggests that there is scope for improving the targeting efficiency of the Thai welfare programmes.

In section 5, we derived two types of PPP indices for groups. $\lambda_{k}$ and $\lambda_{k}^{*}$. The former may be called within-group PPP index as it measures the pro-poorness of a programme within the $k$ th group. The latter may be referred to as total-group PPP index because it captures the impact of operating a programme in the $k$ th group on its pro-poorness at the national level. The results are presented in Table 2. The total-group PPP index shown in the table reveals that the welfare programmes are more pro-poor in the rural areas than in the urban areas. Welfare schemes such as the health-care cards and free school lunches are not pro-poor in the urban areas. This suggests that the government expenditures made on these programmes in the urban areas did not benefit the poor more than the non-poor. 
TABLE 2

Pro-Poor Policy index by urban and rural areas in Thailand, 2000

\begin{tabular}{llccc}
\hline \multirow{2}{*}{ Welfare schemes } & \multicolumn{2}{c}{ Total-group PPP index } & \multicolumn{2}{c}{ Within-group PPP index } \\
& Urban & Rural & Urban & Rural \\
\cline { 2 - 4 } & \multicolumn{2}{c}{ Poverty gap ratio } \\
\hline Social pension for the elderly & 1.13 & 1.76 & 4.41 & 1.31 \\
Low-income medical cards & 1.44 & 2.10 & 5.60 & 1.56 \\
Health insurance cards & 0.70 & 1.39 & 2.72 & 1.03 \\
Free school lunches & 0.81 & 2.21 & 3.15 & 1.17 \\
\hline & & Severity of poverty & 1.63 \\
\hline Social pension for the elderly & 1.18 & 1.60 & 5.42 & 0.99 \\
Low-income medical cards & 1.34 & 2.23 & 6.18 & 1.66 \\
Health insurance cards & 0.61 & 1.36 & 2.83 & 3.37 \\
Free school lunches & 0.73 & 2.27 & \\
\hline
\end{tabular}

It is, however, interesting to note that the within-group PPP index shows that all programmes are more pro-poor in the urban areas than in the rural areas. Thus, the two types of indices (total-group and within-group) present opposite results. The main reason for this is that welfare programmes in Thailand are better targeted in urban than rural areas. Since the concentration of poor is higher in the rural areas, the impact of targeting the rural areas turns out to be more pro-poor at the national level. It is worth stressing that the targeting efficiency of particular group should be judged on the basis of total-group PPP index.

\section{RUSSIA}

Russia has well developed social benefits system, of which pensions are the largest component. Table 3 gives the population in millions receiving some kind of benefits. There are some persons, who receive more than one benefit at the same time but numbers of such people are so small that we have ignored them.

TABLE 3

Russian welfare systems in 2002

\begin{tabular}{lcccc}
\hline Welfare benefits & $\begin{array}{c}\text { Beneficiaries } \\
\text { in million }\end{array}$ & $\begin{array}{c}\text { Percentage } \\
\text { share }\end{array}$ & $\begin{array}{c}\text { Per month cost } \\
\text { in billion (Rubles) }\end{array}$ & $\begin{array}{c}\text { Percentage } \\
\text { share }\end{array}$ \\
\hline Old-age pension & 26.32 & 49.08 & 38.74 & 82.79 \\
Disability pension & 3.19 & 5.96 & 3.61 & 7.71 \\
Loss of breadwinner pension & 1.64 & 3.05 & 1.27 & 2.72 \\
Social pension & 0.27 & 0.5 & 0.26 & 0.56 \\
Care for children under 18 m & 0.84 & 1.57 & 0.41 & 0.88 \\
Children allowance & 17.42 & 32.49 & 1.45 & 3.09 \\
Unemployment benefits & 0.45 & 0.84 & 0.31 & 0.65 \\
Other benefits & 0.95 & 1.77 & 0.2 & 0.42 \\
Scholarship & 2.55 & 4.76 & 0.55 & 1.17 \\
All benefits & 53.63 & 100 & 46.79 & 100 \\
\hline
\end{tabular}


From Table 3 it can be seen that out of the total population of 143.32 million, 53.62 million are receiving some kind of government benefit, which means that 37.41 percent of the total population depends on government benefits. This shows that the Russian social benefits system is very large.

The old-age pension is the largest welfare programme benefiting about 26.32 million people. The second largest program is the children allowance benefiting 17.42 million children. The disability pension is given to 3.19 million people.

The Russian government spends 46.79 billion Rubles per month on welfare programmes (without the administrative costs) of which 38.74 billion Rubles go towards the payment of pensions. The expenditure on children's allowance is only 1.45 billion Rubles, which means that the children's allowance per beneficiary is only 83.1 Rubles per month. Given the fact that the incidence of poverty among children is very severe, the children's allowance is too small to have a significant impact on poverty among children.

The government pays average benefits equal to Rubles 326.5 per person per month. Our average lower poverty line for Russia is Rubles 1055.9 per person per month, which means that the government pays benefits equal to one third of the poverty line.

To what extent do the government benefits go to the poor compared to the non-poor in the Russian Federation? This question is answered through our proposed PPP index. Table 4 gives the empirical estimates of the pro-poorness of each of government welfare programmes that are currently implemented in Russia.

TABLE 4

PPP indices for Russian welfare system in 2002

\begin{tabular}{lll}
\hline Types of government benefits & Poverty gap ratio & Severity of poverty \\
\hline Old-age pension & 2.20 & 4.13 \\
Disability pension & 2.18 & 4.16 \\
Loss-of-breadwinner pension & 2.09 & 2.40 \\
Social pension & 2.22 & 2.80 \\
Care for children under 18 months & 1.78 & 1.87 \\
Children (under 16 years) allowance & 1.19 & 0.79 \\
Unemployment benefits & 2.22 & 3.80 \\
Other benefits & 1.74 & 2.75 \\
Scholarship & 0.90 & 0.62 \\
All benefits & 2.14 & 3.90 \\
& & 5.71 \\
\hline
\end{tabular}

As can be seen from the table, the benefits as a whole have the value of the PPP index far greater than 1. From this, we may conclude that the welfare system in Russia tends to benefit the poor more than the non-poor. More importantly, the absolute benefits of the welfare system do indeed flow more to the ultra-poor than to the poor as suggested by the value of PPP index for the severity of poverty measure, equal to 3.90. Note that the PPP index of all benefits is the weighted average of the PPP indices of all nine welfare programmes, with the weight proportional to the share of each programme presented in the third column of Table 3. 
Table 4 also reveals that if the government of the Russian Federation had implemented perfect targeting, the PPP index would have been 3.02 and 5.71 for the poverty gap and the severity of poverty, respectively. This suggests that although Russian welfare programmes are not perfectly targeted at the poor, their deviation from perfect targeting is not large.

It is important to note that welfare programmes such as the children's allowance given to those aged below 16 years and scholarships are not pro-poor, particularly in relation to the severity of poverty index. This is evident from the result that the PPP indices of these two programmes for the severity of poverty measure fall far below unity. This suggests that the absolute benefits of these programmes do not flow to the ultra-poor. This further suggests that these programmes may require better targeting than the current system in a way that favours the ultra-poor living far below the poverty threshold.

\subsection{HEALTH SERVICES IN VIETNAM}

Over the past decade or so, Vietnam has enjoyed a significant improvement in standard of living with its impressive performance in growth and poverty reduction. More importantly, its growth process has been pro-poor in a way that growth benefits the poor proportionally more than the non-poor (Kakwani and Son 2004). In this context, it will be interesting to see whether, along with a rising standard of living and its pro-poor growth, poor people benefit from the utilization of current health services in Vietnam. Table 5 presents the PPP index for the utilization of various health facilities in Vietnam.

As the results in Table 5 reveal that, only commune health centres show the index value greater than 1. This suggests that the poor utilize commune health centres more than the nonpoor. Unfortunately, commune health centres do not provide quality health services because they are generally poorly staffed and not well equipped. Thus, the poor in Vietnam are generally not receiving the best quality health services.

Public hospitals in Vietnam provide higher quality care and are mainly utilized by individuals with health insurance. It can be noted that the utilization of government hospitals is shown to have a value of PPP index far less than 1, implying that public hospitals in Vietnam provide greater benefits to the non-poor than the poor. As such, the poor are unable to access quality health services that are provided by public hospitals.

TABLE 5

Pro-Poor Policy Index for health services in Vietnam: 1997-98, poverty gap ratio

\begin{tabular}{|c|c|c|c|c|c|}
\hline \multirow{3}{*}{ Health facilities } & & \multicolumn{2}{|c|}{ Total-group PPP index } & \multicolumn{2}{|c|}{ Within-group PPP index } \\
\hline & Vietnam & Urban & Rural & Urban & Rural \\
\hline & \multicolumn{5}{|c|}{ Poverty gap ratio } \\
\hline Government hospitals & 0.62 & 0.07 & 0.91 & 0.34 & 0.74 \\
\hline Commune health centres & 1.17 & 0.27 & 1.23 & 1.38 & 1.00 \\
\hline Regional polyclinics & 0.84 & 0.42 & 0.98 & 2.14 & 0.79 \\
\hline Eastern medicine facilities & 0.96 & 0.04 & 1.15 & 0.21 & 0.94 \\
\hline Pharmacies & 0.96 & 0.26 & 1.16 & 1.29 & 0.94 \\
\hline Private doctors & 0.79 & 0.12 & 0.98 & 0.59 & 0.80 \\
\hline Health insurance & 0.50 & 0.08 & 0.79 & 0.40 & 0.64 \\
\hline Perfect targeting & 2.86 & & & & \\
\hline
\end{tabular}


Nevertheless, it is not surprising to see that the utilization of health insurance is not propoor because in Vietnam, those who are covered by health insurance have access to government hospitals. Moreover, insurance coverage under the health insurance programme is more extensive for relatively better-off individuals. As such, having health insurance is positively correlated with individual income: while the insurance coverage rate is $9.2 \%$ in the bottom income quartile, $24.5 \%$ in the top income quartile have health insurance.

Our results presented in Table 5 indicate that pharmacy utilization is close to being propoor (0.96) when calculated for the poverty gap ratio. It is reasonable to assume that more highly educated individuals, and hence presumably those better aware of the risks of selfmedication, avoid pharmacy visits. As such, pharmacy utilization appears to be an inferior good for the high-income group since rich individuals go to public hospitals for their health care. On the other hand, pharmacy visits are a normal good for poor households.

Table 5 also reveals that as indicated by the total-group PPP index, the utilization of three health facilities is more pro-poor in the rural areas than in the urban areas. These facilities include commune health centres, pharmacies, and eastern medicine facilities. This suggests that government subsidies on these health services in rural areas do benefit poor people more than non-poor ones. In addition, the within-group PPP index indicates that within the urban sector, sick and injured individuals from poor households receive far less benefits from utilization of health care services such as government hospitals and eastern medicine facilities. By comparison, the poor in rural settlements have greater benefits from utilizing facilities such as commune health centres, eastern medicine facilities, and pharmacies.

\subsection{EDUCATIONAL SERVICES IN VIETNAM}

In this subsection, we apply our proposed PPP index methodology to assess educational services in Vietnam. Our prime objective is to find out to what extent public education at primary and secondary levels is pro-poor. We also seek answering whether free universal education will benefit the poor more than the non-poor.

TABLE 6

Pro-Poor Policy Index for education service in Vietnam: 1997-98

\begin{tabular}{lccc}
\hline \multirow{2}{*}{ School types } & Primary & Lower secondary & Upper secondary \\
\cline { 2 - 4 } & & Poverty gap ratio & 0.37 \\
Public & 1.29 & 0.79 & 0.23 \\
Semi-public & 0.55 & 0.15 & 0.00 \\
\hline Sponsored & 0.63 & 0.51 & 0.23 \\
\hline Public & & Severity of poverty & 0.09 \\
Semi-public & 1.31 & 0.65 & 0.00 \\
Sponsored & 0.19 & 0.08 & 0.26 \\
\hline
\end{tabular}


TABLE 7

Pro-Poor Policy Index if universal education is provided in Vietnam

\begin{tabular}{lcc}
\hline & Poverty gap ratio & Severity of poverty \\
\hline Primary & 1.28 & 1.33 \\
Lower secondary & 1.08 & 1.06 \\
Upper secondary & 0.91 & 0.85 \\
\hline
\end{tabular}

Table 6 reveals that public primary education benefits the poor more than the non-poor. Benefits provided by public primary education are even more pro-poor for the ultra-poor in Vietnam. This is supported by the fact that net enrolments in primary school increased from 87 to 91 percent over the period 1993-1998 (Nguyen 2002). Coupled with substantial improvement in primary school enrolment rates, changes in the allocation of public spending on education in the 1990s could have further favoured lower levels of education. The share of public spending on education going to the poor increased from 16.5 percent in 1993 to 18.1 percent in 1998 (Nguyen 2002). Although public schools at the primary education level are found to be pro-poor, other types of schools at the same level are highly anti-poor. In other words, primary schools, which are semi-public or sponsored by the private sector, benefit better-off children more than poor ones. This suggests that educational subsidies given to these types of schools are likely to benefit the non-poor more than the poor.

As shown in Table 6, lower secondary education in Vietnam is not pro-poor as indicated by the PPP index. This finding emerges consistently irrespective of school types. At the lower secondary level, net enrolment rates more than doubled in Vietnam between 1993 and 1998, to 30 percent and 62 percent, respectively. However, for the population as a whole, 38 percent of children aged 11-14 years were not enrolled in lower secondary school, and 66 percent of the poorest children in this age range were not enrolled in primary school. The disparity in the enrolments rates between the richest and poorest quintiles is highly distinctive over the years.

As would be expected, the PPP index signals that upper secondary schools strongly favour children from the better-off households compared to those from poor ones. This is consistent with all types of schools at this level. Note that there are no children from poor households enrolled in the upper secondary level schools sponsored by the private sector. Over the period 1993-98, children from the poorest quintile experienced an increase in enrolment in upper secondary schools from 1 to 5 percent as compared to an increase from 21 to 64 percent for the richest quintile (Nguyen 2002). On the whole, much still needs to be done to achieve universal primary and secondary education in Vietnam. Having said that, we follow up with the question of whether universal education can really deliver educational outcomes that are pro-poor. The PPP index under a system of universal education is compared to that under the current education system.

Table 7 shows that universal education at primary and lower secondary levels will provide more benefits to the poor children than to non-poor ones. The degree of pro-poorness of universal access to primary education among 6- to 10-year-old children is almost as high as that actually obtained from the current education system in Vietnam. Similarly, if lower secondary education is made universal for children aged between 11 and 14 years, it will provide pro-poor outcomes. This is in contrast with the result obtained from the actual situation as indicated by the PPP index: the index is 0.79 in the current lower secondary 
education, whereas it is 1.08 when lower secondary education is universal. At higher levels, its universal provision is not likely to deliver pro-poor outcomes. The PPP index for upper secondary is shown to be less than unity. In short, universal education at higher levels will not be pro-poor, but will provide greater opportunities to poor individuals aged between 15 and 17 at the upper secondary level to have greater access to higher education compared to the current situation in Vietnam.

\subsection{BASIC INFRASTRUCTURE SERVICES IN VIETNAM}

Basic infrastructure services make significant contributions to people's well-being. Basic services such as piped water and sanitation (e.g. sewerage systems, flushing toilets, etc) have direct impacts on people's health status and overall well-being. Having access to other services like electricity and telephones helps households to increase their productivity for income generation. A number of studies reveal that a household's access to basic services is highly and significantly correlated with a lower probability of being poor.

TABLE 8

Pro-Poor Policy Index for basic infrastructure service in Vietnam: 1997-98

\begin{tabular}{lcc}
\hline Access to basic infrastructure services & Poverty gap ratio & Severity of poverty \\
\hline Electricity & 0.80 & 0.71 \\
Piped and tap water & 0.86 & 0.81 \\
Collected waste & 0.10 & 0.07 \\
Sanitary toilets & 0.10 & 0.05 \\
\hline
\end{tabular}

As shown in Table 8, in Vietnam the benefits generated from all types of basic services go to the non-poor more than the poor. Poor households in general have much greater access to piped water and electricity than sanitary systems: the PPP index for water and electricity are 0.86 and 0.80 , respectively, when measured by the poverty gap ratio, whereas the indices for the other services are just 0.10 for sanitary facilities. As suggested in Table 8 , benefits generated from sanitary services (collected waste and flushing toilets in this case) are highly skewed in favour of the non-poor. The benefits of all types of basic services are lower for the severity of poverty measure. This suggests that the ultra-poor have even lower access to the basic infrastructure services than the poor.

\section{CASE STUDIES II: 15 AFRICAN COUNTRIES}

The study utilizes the unit-record household data sets from 15 African countries. These data sets were obtained from the African Household Survey Data Bank of the World Bank. The countries and year of the survey include: Burundi in 1998, Burkina Faso in 1998, Ivory Coast in 1998, Cameroon in 1996, Ethiopia in 2000, Ghana in 1998, Guinea in 1994, Gambia in 1998, Kenya in 1997, Madagascar in 2001, Mozambique in 1996, Malawi in 1997, Nigeria in 1996, Uganda in 1999, and Zambia in 1998. 
The study uses the national poverty lines for the 15 countries, which have been obtained from various poverty assessment reports. These poverty lines were originally very crude, and did not take into account different needs of household members by age and gender. What is more, these poverty lines were not adjusted for the economies of scale which exist in large households. To overcome these shortcomings stemming from the official poverty lines, Kakwani and Subbarao (2005) made some modifications to the national poverty lines taking into account different needs of household members and economies of scale.

\subsection{TARGETING CHILDREN: TARGETING VS. UNIVERSAL}

According to Coady, Grosh, and Hoddinott (2002), more than a quarter of targeted programmes in developing countries overall had regressive benefit incidence. For instance, they found that the poorest 40 percent of the income distribution was receiving less than $\mathbf{4 0}$ percent of poverty alleviation budgets. Such ineffective targeting of poor households suggests that the overall impact on poverty is much smaller than that it would have been if well targeted. Moreover, administrative costs involved in implementing any targeted programmes are very high. Much of the budget is spent on simply getting the resources to poor families. Consequently, the cost per unit of income transferred can be substantially large. Transfer programmes seem to be administratively complex as they require resources to undertake targeting of transfers and to monitor the recipients' actions. In this context, one might argue for a scenario of universal transfers.

In this section, we estimate the PPP indices under a universal transfer programme for the children aged between 5 and 16 years old. Under this programme, every child in this age group is assumed to receive a certain amount of transfer, irrespective of their poverty status. The results are presented in both Figure 1 and Table 9.

From Figures 1 and 2, it is important to note that the value of PPP index with perfect targeting is quite small compared to the index values shown for Thailand, Russia, and Vietnam. In fact, the PPP indices under perfect targeting show a small difference from the indices resulted from universal transfers. This suggests that perfect targeting may not be necessary in cases like these 15 African countries, where poverty is extremely high. 
FIGURE 1

Pro-Poor Policy indices under universal transfers and perfect targeting (poverty gap ratio)

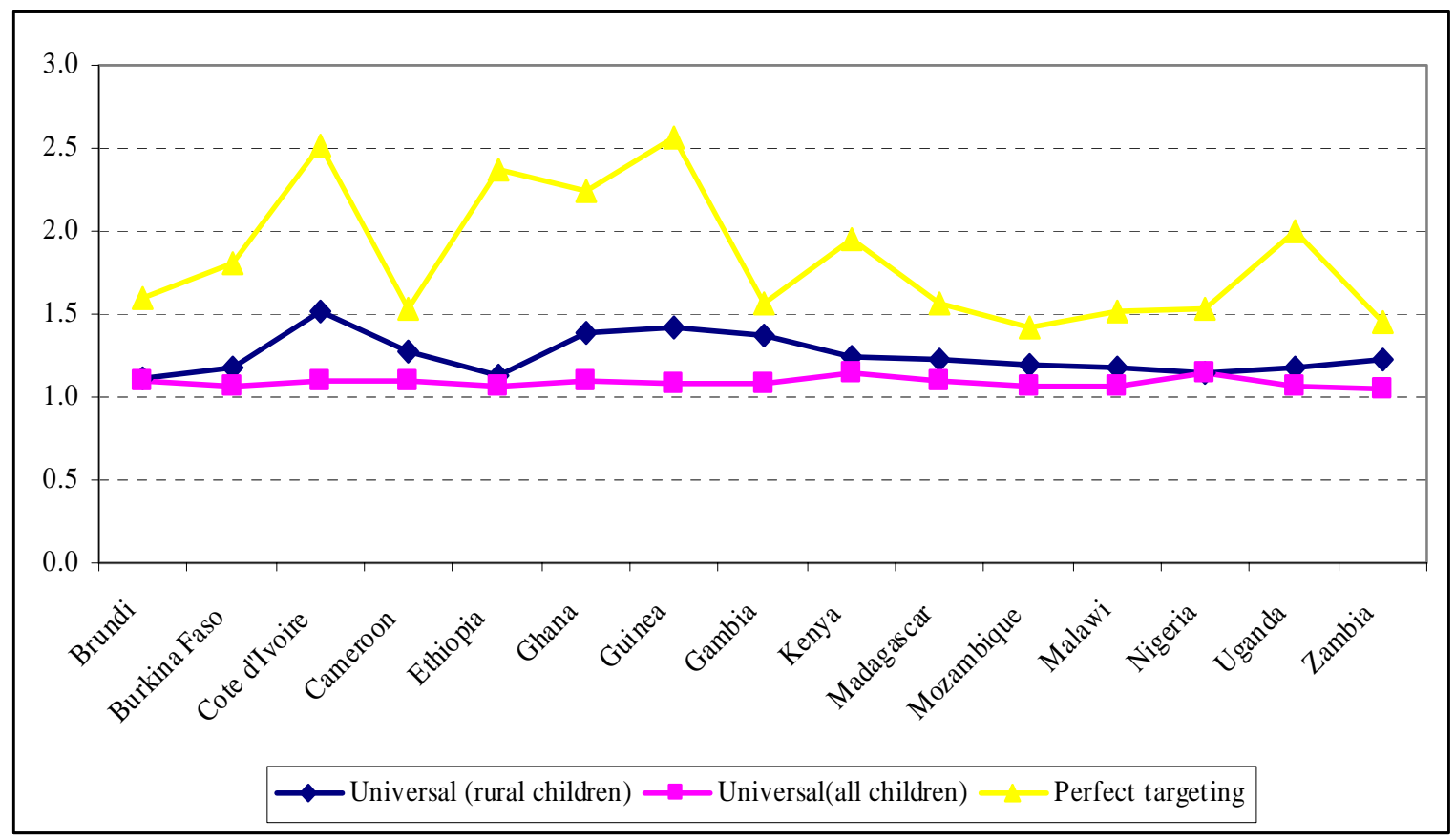

FIGURE 2

PPP indices under perfect targeting for 18 countries (poverty gap ratio)

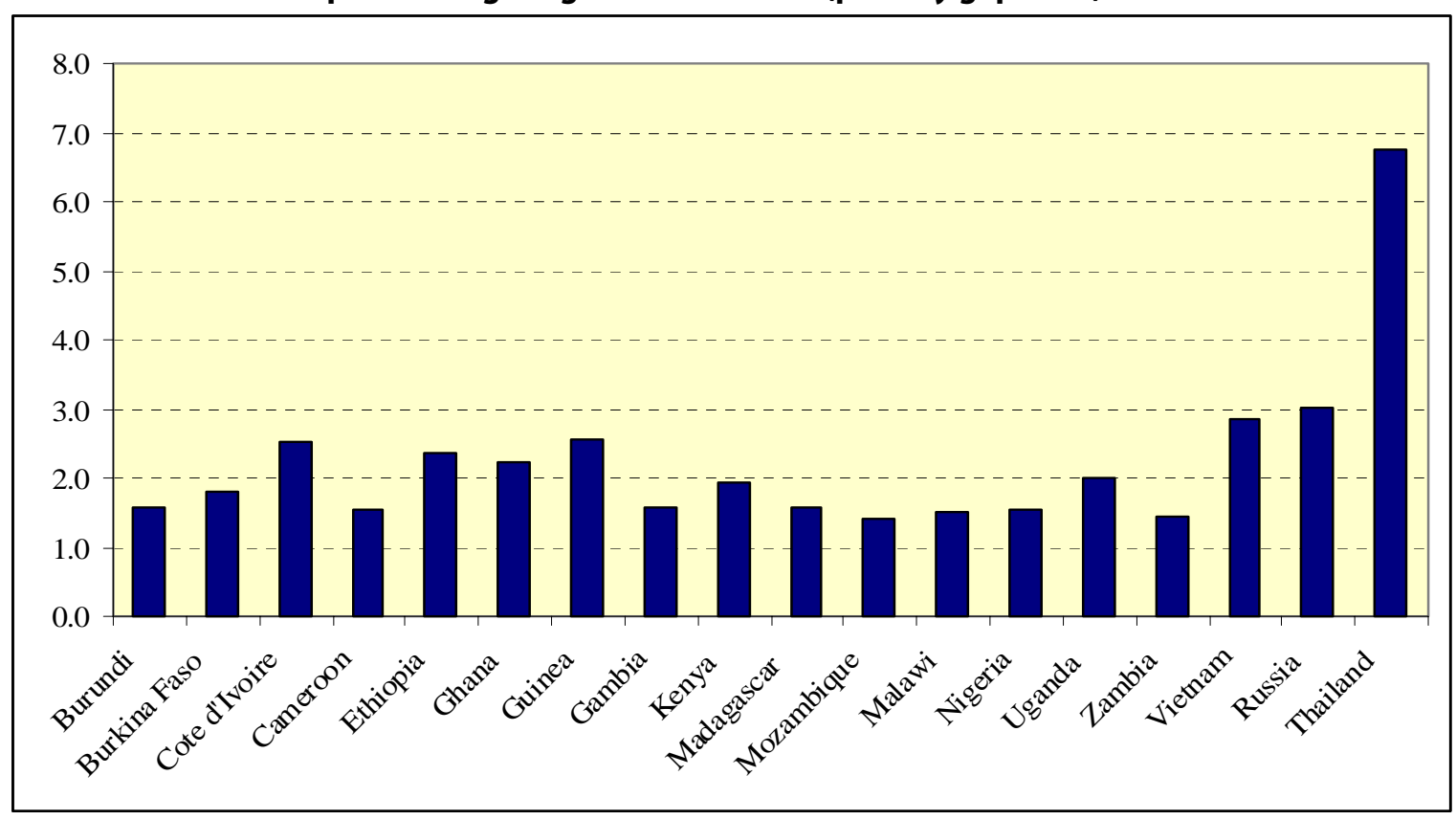


Table 9

Pro-Poor Policy index for universal transfers to rural and urban areas

\begin{tabular}{|c|c|c|c|c|c|c|c|c|}
\hline \multirow{3}{*}{ Country } & \multicolumn{4}{|c|}{ Poverty gap ratio } & \multicolumn{4}{|c|}{ Severity of poverty } \\
\hline & \multicolumn{3}{|c|}{ Universal targeting } & \multirow{2}{*}{$\begin{array}{c}\text { Perfect } \\
\text { targeting }\end{array}$} & \multicolumn{3}{|c|}{ Universal targeting } & \multirow{2}{*}{$\begin{array}{l}\text { Perfect } \\
\text { targeting }\end{array}$} \\
\hline & Rural & Urban & Total & & Rural & Urban & Total & \\
\hline Burundi & 1.12 & 0.28 & 1.09 & 1.59 & 1.16 & 0.23 & 1.12 & 2.11 \\
\hline Burkina Faso & 1.18 & 0.43 & 1.07 & 1.81 & 1.21 & 0.38 & 1.08 & 2.53 \\
\hline Cote d'Ivoire & 1.51 & 0.60 & 1.10 & 2.51 & 1.63 & 0.45 & 1.09 & 3.63 \\
\hline Cameroon & 1.28 & 0.60 & 1.09 & 1.54 & 1.32 & 0.50 & 1.08 & 2.05 \\
\hline Ethiopia & 1.13 & 0.73 & 1.07 & 2.37 & 1.14 & 0.74 & 1.09 & 3.42 \\
\hline Ghana & 1.39 & 0.54 & 1.09 & 2.24 & 1.47 & 0.42 & 1.10 & 3.03 \\
\hline Guinea & 1.42 & 0.37 & 1.08 & 2.56 & 1.47 & 0.31 & 1.10 & 3.40 \\
\hline Gambia & 1.37 & 0.65 & 1.08 & 1.56 & 1.56 & 0.39 & 1.08 & 2.00 \\
\hline Kenya & 1.25 & 0.29 & 1.14 & 1.95 & 1.27 & 0.18 & 1.16 & 2.53 \\
\hline Madagascar & 1.22 & 0.65 & 1.09 & 1.57 & 1.29 & 0.57 & 1.13 & 1.95 \\
\hline Mozambique & 1.19 & 0.62 & 1.07 & 1.42 & 1.24 & 0.59 & 1.11 & 1.77 \\
\hline Malawi & 1.17 & 0.18 & 1.07 & 1.52 & 1.21 & 0.09 & 1.09 & 1.93 \\
\hline Nigeria & 1.14 & 1.13 & 1.14 & 1.54 & 1.12 & 1.21 & 1.16 & 1.91 \\
\hline Uganda & 1.17 & 0.25 & 1.06 & 2.00 & 1.20 & 0.19 & 1.08 & 2.75 \\
\hline Zambia & 1.23 & 0.76 & 1.05 & 1.45 & 1.34 & 0.57 & 1.06 & 1.80 \\
\hline
\end{tabular}

Table 9 carries two important messages. Firstly, the results indicate that universal transfers will provide more absolute benefits to children from poor families than those from non-poor families. Secondly, a universal-transfer scheme is likely to bring even more pro-poor outcome if it is implemented in the rural areas where most of poor children are. One exception is Nigeria. This occurs because poverty in Nigeria is widespread over both the urban and rural areas, whereas in the other countries it is predominant in rural areas.

One criticism of this methodology is that we do not have actual scenario that can compare targeted transfers with universal transfers. Nevertheless, the main implication emerging from the PPP index is that if a transfer is given to every child aged between 5-16 years old, it is likely to provide more absolute benefits to poor children, particularly in rural areas. What is more, this analysis suggests that universal targeting of children may not be a bad policy option in rural areas in particular. This may be more cost effective as targeting only a small subgroup of children may involve large administrative costs in identifying the poor ones.

\subsection{FOOD SUBSIDIES}

Food subsidy programmes are under increasing scrutiny in many developing countries because their contributions to government budget deficits are in general large. According to critics, food subsidies pose both an unnecessary burden on the public budget and are economically inefficient as their benefits do not often accrue to the poor. These critics argue that due to improper targeting, a large part of food subsidies is leaked to better-off people in society. 
Proponents of food subsidies argue, however, that such programmes are necessary to guarantee the supply of basic foods to the poor. Proponents claim that food subsidies are needed to protect the welfare and nutritional status of the economically disadvantaged because poor people spend higher proportions of their income on food than do rich ones.

Do food subsidy programmes benefit the poor or needy groups? Are the benefits of these programmes leaked to non-needy groups, such as high-income households? Are food subsidies to the population more (or less) pro-poor compared to food stamps targeted to the poor? Using the proposed PPP index, this subsection attempts to address these issues within the context of 15 African countries. Food subsidy programmes are designed to sell and/or make available food items to consumers at below-market prices. This implies that benefits received by the consumers are proportional to their food consumption. Figure 3 illustrates PPP indices calculated for both poverty gap and severity of poverty.

FIGURE 3

PPP indices for a food subsidy programme

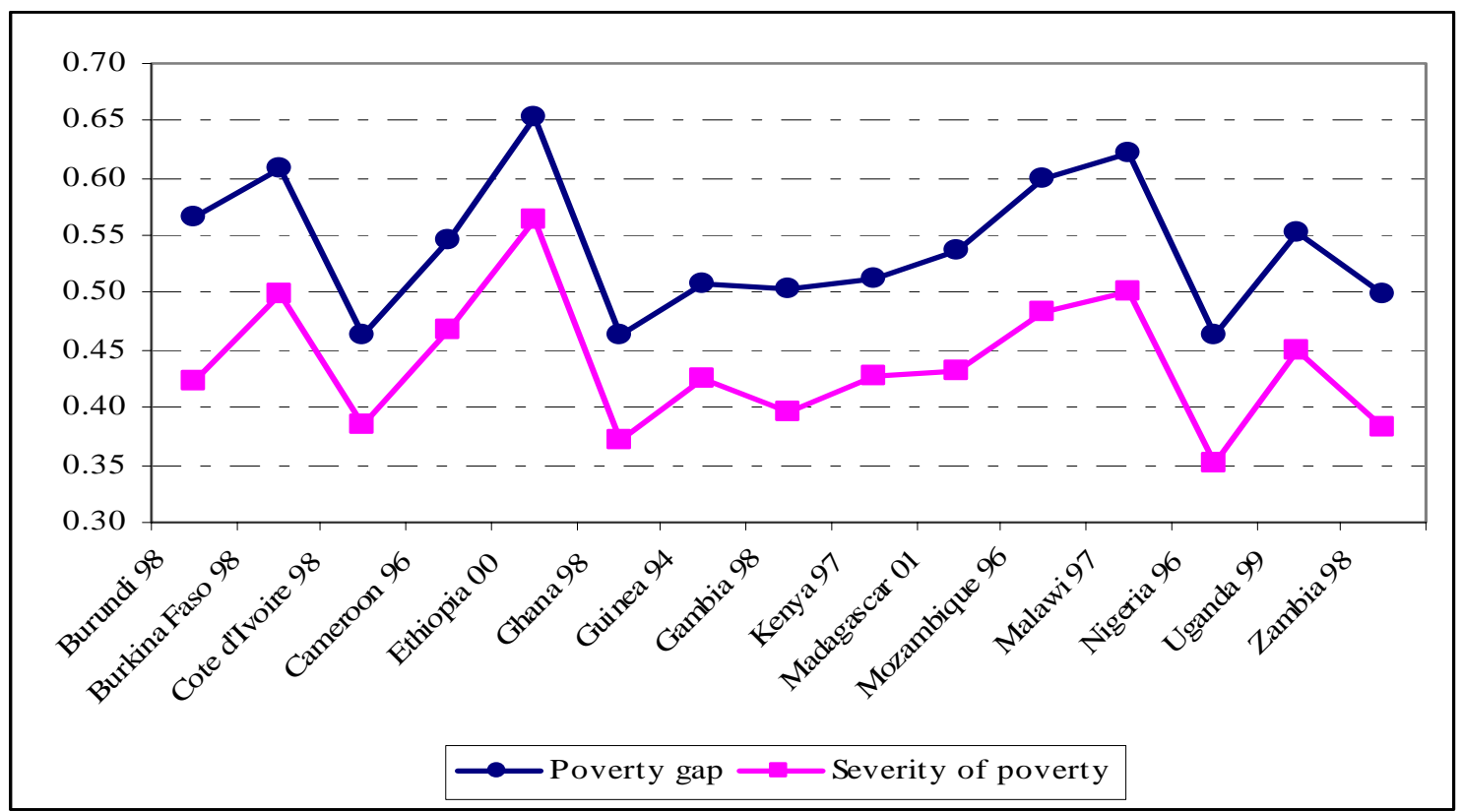

As clearly presented in the figure, the PPP index for food subsidies is far below 1 for all the 15 African countries considered. Figure 3 states that food subsidy, if given to all, benefits the non-poor more than the poor. What is worse, the extent to which the benefits of these programmes are leaked to the non-poor tends to be greater if ultra-poor people receive a greater weighting. This suggests that food subsidy programmes in African countries may not be a good policy option from a pro-poor policy perspective.

Many countries have introduced food stamps in order to target food subsidies to the poor. In Jamaica, for example, poor people get food stamps at health clinics. Food stamp programmes will obviously involve administrative costs in selecting their beneficiaries. Given the administrative costs, we have calculated the degree of pro-poorness for food stamps targeting the poor. The results are presented in Table 10. 
According to Table 10, food stamps given to the poor will bring a highly pro-poor outcome. This is true for all the 15 countries. This suggests that if food stamps are provided and targeted to the poor, their benefits will be received by the poor much more than the nonpoor. All in all, food stamps given to the poor are much more pro-poor compared to food subsidy programmes in general. However, there will be administrative costs involved in identifying the poor who are the beneficiaries of food stamp programme.

TABLE 10

PPP index for giving food stamps to poor

\begin{tabular}{lcccc}
\hline & \multicolumn{2}{c}{ PPP index } & \multicolumn{2}{c}{ Maximum value } \\
\cline { 2 - 5 } & Poverty gap ratio & Severity of poverty & Poverty gap ratio & Severity of poverty \\
\hline Burundi 98 & 1.59 & 1.19 & 1.63 & 2.11 \\
Burkina Faso 98 & 1.85 & 1.51 & 1.90 & 2.53 \\
Cote d'Ivoire 98 & 2.56 & 2.13 & 2.72 & 3.63 \\
Cameroon 96 & 1.54 & 1.32 & 1.64 & 2.05 \\
Ethiopia 00 & 2.39 & 2.06 & 2.45 & 3.42 \\
Ghana 98 & 2.22 & 1.77 & 2.30 & 3.03 \\
Guinea 94 & 2.56 & 2.14 & 2.63 & 3.40 \\
Gambia 98 & 1.53 & 1.21 & 1.61 & 2.00 \\
Kenya 97 & 1.95 & 1.63 & 2.01 & 2.53 \\
Madagascar 01 & 1.56 & 1.25 & 1.61 & 1.95 \\
Mozambique 96 & 1.40 & 1.13 & 1.45 & 1.77 \\
Malawi 97 & 1.52 & 1.22 & 1.56 & 1.93 \\
Nigeria 96 & 1.48 & 1.12 & 1.58 & 1.91 \\
Uganda 99 & 2.02 & 1.65 & 2.08 & 2.75 \\
Zambia 98 & 1.45 & 1.12 & 1.50 & 1.80 \\
\hline
\end{tabular}

\section{CONCLUSIONS}

This paper has proposed a new index called the Pro-Poor Policy (PPP) index. This index measures the pro-poorness of government welfare programmes and basic service delivery in education, health and infrastructure. It is an attempt to introduce a methodology in assessing the techniques of targeting, to make it better suited for evaluation.

If our objective is to reduce poverty, then social transfer programmes should be designed in such a way that they lead to the maximum reduction in poverty under given resource constraints. To achieve this objective, perfect targeting would be an ideal solution. Two prerequisites are necessary in this context: first that only the poor get all the benefits and, second, that benefits given to the poor are proportional to their income shortfalls in relation to the poverty line. To implement such a programme, we will need to have detailed information of people's income or consumption expenditure. Such detailed information and the administrative abilities to use it are of course not present in most developing countries. So the policy makers have to resort to a form of proxy targeting which makes the transfers based on easily absorbable socioeconomic characteristics of the household. The proxy targeting can never achieve complete targeting success. In this respect, this study is an important methodological attempt to assess the targeting efficiency of government programmes by trying to find out how good the proxy targeting is, as compared to perfect targeting. 
Using micro unit-record household surveys, the proposed methodology was applied to 18 countries including Thailand, Russia, Vietnam, and 15 African countries. Major conclusions emerging from our empirical analysis can be synthesized as follows:

Firstly, all the four welfare programmes implemented recently by the Thai government, i.e. social pensions for elderly, low income medical card, health insurance card and free school lunch, were found to be pro-poor. In particular, welfare programmes designed to help the very poor - including low income medical cards and free school lunches - were shown to be highly pro-poor, benefiting the ultra-poor more than the poor. In addition, our study has shown that the universal pension for those over 65 years of age is likely to be less pro-poor than the present old-age pension system. This suggests that the Thai government should continue with its present old-age pension scheme.

Second, the study found that the welfare system in Russia tends to benefit the poor more than the non-poor. Moreover, the absolute benefits of the welfare system do indeed flow more to the ultra-poor than to the poor as suggested by a higher value of PPP index for the severity of poverty than the index value for the poverty gap. Furthermore, the study found that the overall Russian welfare programmes are reasonably well-targeted. This was evident from the finding that the values of PPP indices of welfare programmes are quite close to (but still lower than) the expected value of index under perfect targeting. The study also found that welfare programmes - such as children-allowance given to those aged below 16 years and scholarships - are not pro-poor for the ultra-poor in particular. This suggests that these programmes may require a better targeting than the current system in a way that favours the ultra-poor living far below the poverty threshold.

Third, basic services - health and education - in Vietnam were found to be mostly not pro-poor. From the health perspective, although government hospitals provide the highest quality of health care, the poor are unlikely to utilize them. This is, however, not true for commune health centres which appear to provide more services to individuals from poor households. Unfortunately, commune health centres do not provide high quality health services because they are in general poorly staffed and equipped. On the whole, the poor in Vietnam have less access to quality health care. However, public primary schools in Vietnam were found to be pro-poor. This was due partly to the increase in public spending on education for the poor in the 1990s. In contrast, secondary education in Vietnam was found to be not pro-poor. What is more, the Vietnamese study has indicated that universal education at primary and lower secondary levels can provide more benefits to students from poor households, but this cannot be said for higher levels of education.

Fourth, the study discussed ex-ante simulations of universal cash transfers to school agegroup children in the 15 African countries. The results indicated that universal transfers will provide more absolute benefits to children from poor families than those from non-poor families. In addition, the study found that universal-transfer scheme is likely to bring even more pro-poor outcome if it is implemented in the rural areas where most poor children reside. This finding was true for all the countries except for Nigeria, where poverty is widespread over both the urban and rural areas, while poverty is acute mainly in rural areas in the other countries.

Fifth, the study found that in the 15 African countries, the value of PPP index with perfect targeting was quite small compared to the index values estimated for Thailand, Russia, and Vietnam. The index value of perfect targeting for Thailand was far greater than that of perfect 
targeting for countries like Russia and Vietnam. In fact, in the case of the African countries the PPP indices under perfect targeting showed a small difference from the indices resulting from universal targeting of the children. Therefore, we may conclude that perfect targeting is not necessary for cases like these 15 African countries, where poverty is extremely high.

Finally, the study found that if food subsidy programmes are implemented through selling and/or making available food items to consumers at below-market prices, their absolute benefits are likely to go to rich people more than to poor ones within the context of the 15 African countries. Our finding suggests that food subsidies may not be a good policy option in the sense that their benefits are not received by the poor. Nevertheless, the study found that food stamps targeted to the poor are highly pro-poor. 


\section{REFERENCES}

Foster, J., Greer, J. and Thorbecke, E. (1984) "A Class of Decomposable Poverty Measures", Econometrica 52, no.3, 761-66

Grosh, M. (1994) Administering Targeted Social Programmes in Latin America: From Platitudes to Practice. World Bank Regional and Sectoral Studies. Washington, D.C.: World Bank

Haddad, L. J. and Kanbur, R. (1991) "Intra-household Inequality and the Theory of Targeting" Policy, Research, and External Affairs Working Paper, World Bank: Washington, D.C.

Jimenez, E. (1993) "Cash versus In-kind Transfers." Lecture Notes, EDI seminar on Labor Market and the Social Safety Net in the Former Soviet Union/CIS countries, World Bank, Washington, D.C.

Kakwani, N. and Son, Hyun, H. (2004) "Pro-Poor Growth: Asian Experience", International Poverty Centre-UNDP working paper: Brazil

Nguyen, N. N. (2002) "Trends in the Education Sector from 1993 - 1998", World Bank Policy Research Working Paper, World Bank: Washington D.C.

Rodriguez, A. and C. A. Herran (2000) Secondary Education in Brazil. Inter-American Development Bank, Washington D.C.

Tabor, S. R. (2002) "Assisting the Poor with Cash: Design and Implementation of Social Transfer Programmes" Social Protection Discussion Paper, World Bank: Washington D.C.

Trivedi, P. (2002) "Patterns of Health Care Utilization in Vietnam", World Bank Policy Research Working Paper, World Bank: Washington D.C. 


\section{NOTES}

1. It must be pointed out that $\lambda_{m}$ is not an upper bound of $\lambda$. Suppose we give a fixed amount of transfer only to poor, then $\mathrm{b}(\mathrm{x})=\mathrm{b}$ (if $\mathrm{x}<\mathrm{z}$ ) and 0 otherwise. From this, it can be easily seen that $\lambda=1 / H$ for the entire class of additive and separable poverty measures as defined in (1). In some cases, this programme may give larger values of $\lambda$ compared to the case of perfect targeting.

2. For a detailed discussion on Thailand and Russian poverty lines, see Kakwani $(2000,2004)$. 
International Poverty Centre SBS - Ed. BNDES, $10^{\circ}$ andar 70076900 Brasilia DF Brazil

povertycentre@undp-povertycentre.org www.undp.org/povertycentre

Telephone +55 6121055000

Fax +55 6121055001 